\title{
EL MODELO DE IDENTIDAD DEL REINO DE MALLORCA EN LA BAJA EDAD MEDIA
}

\author{
Luis Tudela Villalonga ${ }^{1}$ \\ CA UNED Islas Baleares
}

\section{RESUMEN}

El Reino de Mallorca definió su modelo de identidad a lo largo de la Baja Edad Media. En este período fue creando sus rasgos más característicos en diversas esferas como el institucional, el territorial, el judicial, o el fiscal entre otros. En el siglo XIII, la ocupación cristiana de las Islas Baleares fijó el marco regulador de convivencia de los repobladores y propició la creación de una nueva administración a todos los niveles, mientras que la dinastía privativa mallorquina favoreció la proyección de la imagen a nivel interior y exterior del Reino de Mallorca, y la consolidación de la organización institucional en aquellas zonas en las que aún era incipiente. Sin embargo, no todos los procesos tuvieron éxito. La heterogeneidad de los territorios que componían el Reino de Mallorca no permitió la construcción de una identidad nacional.

Palabras clave: Imagen, Reino de Mallorca, administración, espacio territorial, ocupación cristiana, carta de franquicia.

\section{ABSTRACT}

The Kingdom of Mallorca defined its model of identity through the Late Middle Ages. In this period, it was creating its most characteristic features in various areas such as institutional, territorial, judicial, or fiscal among others. In the

1 Doctor en Historia. Profesor Tutor. Universidad Nacional de Educación a Distancia (UNED). Centro Asociado Illes Balears.07009. Palma de Mallorca. C.e.: lluis_tudela@yahoo.es. Abreviaturas utilizadas: ARM. Arxiu del Regne de Mallorca, ACM. Arxiu Capitular de la Catderal de Mallorca. 
thirteen Century, the Christian occupation of the Balearic Islands set the regulatory framework of coexistence of settlers and encouraged the creation of a new administration at all levels, while Majorcan dynasty favoured the projected level image inside and outside of the Kingdom of Mallorca, and the consolidation of the institutional organization in those areas where it was still incipient. However, not all processes were successful. The heterogeneity of the territories that made up the Kingdom of Mallorca didn't allow the construction of a national identity.

Keywords: Image, Kingdom of Mallorca, administration, territorial space, Christian occupation, letter of franchise.

\section{INTRODUCCIÓN}

El Reino de Mallorca desarrolló una identidad propia al igual que otros Estados cristianos que fueron surgiendo en la Península Ibérica durante la Edad Media. ${ }^{2}$ Los sucesivos gobernantes mallorquines fueron creando un modelo, original en algunos aspectos, pero también influenciado por los vaivenes de la política exterior mallorquina y la mediatización política ejercida por los Estados próximos.

El modelo de identidad del Reino de Mallorca se construyó durante la Baja Edad Media. Hasta el siglo XIII, las Islas Baleares se encontraban bajo el control musulmán. Con la ocupación de Mallorca, la política de los cristianos fue transformando el modelo de sociedad existente hasta entonces, como sucedería en las restantes islas. Las modificaciones fueron profundas. Se introdujeron nuevas fórmulas de distribución de la tierra, como el feudo y la caballería, y surgieron las primeras normativas e instituciones que regulaban los derechos y deberes de los nuevos pobladores cristianos. Se transformó el sistema fiscal, y se produjeron cambios significativos en la estructura social, con la modificación del rol de los musulmanes. De forma progresiva, se fueron sustituyendo determinados cultivos de regadío ampliamente extendidos en la época musulmana como el arroz y el algodón, por una agricultura extensiva de secano basada en los cereales, el olivo y la viña.

El ámbito urbano también experimentó cambios tras la ocupación cristiana. La mayoría de las ciudades modificaron su diseño urbanístico e imagen visual. A principios del siglo XIV, nuevas construcciones suntuosas en las principales ciudades mallorquinas dibujaron un paisaje urbano muy distinto al existente un

2 Véase el artículo de DEL VAL VALDIVIESO, I., «La identidad urbana al final de la Edad Media», en Anales de Historia Medieval de la Europa Atlántica, 1, Santander, 2006, pp. 5-29, donde analiza la constitución de los sentimientos de identidad común y sus consecuencias en los núcleos urbanos en la Corona de Castilla. 
siglo antes. Además, los dirigentes cristianos dotaron de nuevas infraestructuras y servicios a las ciudades ya existentes, fundaron nuevas villas, y constituyeron y consolidaron el sistema municipal, especialmente en las Islas Baleares. Sus disposiciones fortalecieron la identidad urbana en el Reino de Mallorca. Favorecieron los sentimientos de pertenencia y vinculación de los habitantes con sus respectivas ciudades y villas, a la vez que propiciaron un progresivo traslado de la población del campo a la urbe.

La fijación de un espacio territorial también se realizó de forma gradual. Hasta la muerte de Jaime I, el Reino de Mallorca se identificaba con las islas de Mallorca e Ibiza. A partir de 1276, se ampliaría a un conjunto de territorios situados en el norte de Cataluña, con una nueva Corona y dinastía Real. En 1287, se incorporaba Menorca al Reino. Medio siglo después, la acción militar de Pedro IV el Ceremonioso conllevaría la anexión de la mayoría de estos territorios a la Corona de Aragón, con la notable excepción de Montpellier, y la desaparición de la Corona de Mallorca.

De esta manera, se fueron creando distintas identidades, urbana, territorial, nacional o institucional, que acabarían perfilando el modelo mallorquín. La propia evolución histórica de los territorios acabaría definiendo la personalidad y los rasgos más significativos e identificativos del Reino de Mallorca.

\section{LA ORGANIZACIÓN INSTITUCIONAL DEL REINO DE MALLORCA: EL DESARROLLO DE LAS NORMATIVAS Y SU REGULACIÓN}

Como es conocido, el rey aragonés Jaime I conseguía entrar en Madina Mayurqa, la capital musulmana balear, el 31 de diciembre del 1229. Habían transcurrido 117 días desde el día que había partido la flota cristiana desde Salou y Tarragona, y más de 100 desde que sus fuerzas habían iniciado el asedio final de Madina Mayurqa.

Una vez tomada Madina Mayurqa, Jaime I se proclamó simbólicamente soberano del Reino de Mallorca, aunque sólo ejercía el dominio efectivo sobre un territorio muy reducido. No obstante, el monarca cristiano ya controlaba la ciudad más importante y había derrotado a la principal fuerza militar del walí Abu Yahya. Seguro de su victoria, Jaime I abandonó la isla con cierta rapidez y dejó el mando de las operaciones finales a Bernat de Santa Eugenia, lugarteniente real, a pesar de que algunos musulmanes continuaron la resistencia desde las montañas.

No obstante, en los nueve meses que Jaime I estuvo en Mallorca, tomó importantes decisiones que regularían el marco jurídico y administrativo del nuevo Reino de Mallorca, y reordenarían el territorio. De esta manera, el Reino de Mallorca comenzaría a adquirir identidad propia. 
Como nuevo soberano del territorio conquistado, Jaime I estableció una administración Real embrionaria que sustituiría el modelo organizativo musulmán. La administración tenía una estructura piramidal conformada por diversos oficiales públicos. Al frente de la isla de Mallorca, Jaime I colocó a un Lugarteniente o Llochtinent, quien actuaba como máximo representante de la Corona durante su ausencia. Tenía poderes similares al del monarca, y diversos cometidos políticos, militares y judiciales en materia de apelación. El Llochtinent solía contar con un asesor, especialista en derecho, para poder gestionar mejor la administración judicial, y un consejo de prohombres para tratar las apelaciones. Eivissa y Menorca también tuvieron un lugarteniente, tras las conquistas cristianas.

A partir de 1343, Pedro IV, después de incorporar el Reino de Mallorca a la Corona de Aragón, decidió sustituir semánticamente la palabra Lugarteniente por Gobernador, quien mantuvo y amplió las competencias que tenía su equivalente. ${ }^{3}$

Por debajo del Llochtinent, ${ }^{4}$ se situaban el Batlle con diversas competencias relacionadas con el orden público, la justicia y la administración; y el Veguer con atribuciones judiciales. Ambos oficiales Reales se establecieron en cada isla, convertido en distrito único en esta época. No obstante, en 1300, el rey Jaime II creó la figura del Veguer de Fora que tendría jurisdicción sobre los habitantes de las villas foráneas mallorquinas.

El esquema organizativo propuesto por Jaime I para la administración Real se complementó con otras medidas, como fue el impulso dado a la llegada y al asentamiento de cristianos en la isla de Mallorca. La concesión de una carta de franquicia o poblacional a los nuevos pobladores se revelaba como la mejor solución para estimular su presencia en el territorio, tal y como habían hecho los reyes aragoneses en otras áreas reconquistadas a los musulmanes desde mediados del siglo XII.

En un tiempo relativamente breve, apenas dos meses desde el asalto a Madina Mayurqa, Jaime I promulgaba la Carta de Franquesa, después que hubiese sido redactada por un jurista laico y un canónigo. La Carta contiene 37 artículos que definen algunos aspectos de la propia identidad del Reino de Mallorca. Incluye

3 CATEURA BENNASSER, P., «La Gobernación del Reino de Mallorca» en Anales de la Universidad de Alicante, Historia Medieval, 12, Alicante, 1999, p. 90. El autor también comenta que en época de Alfonso el Liberal, el lugarteniente se denominó procurador- lugarteniente, desplazando al Batlle en el control del municipio, op. cit. p. 86.

4 En época de los reyes de Mallorca, el Procurador Real acabaría situándose por encima del Batlle y Veguer, ocupando la segunda magistratura del Reino de Mallorca. Tenía como función principal la administración del Real Patrimonio. Puede consultarse en CONDE DELGADO DE MOLINA, R:, «La estructura de la administración Real en la isla de Mallorca, circa 1358», Mayurqa, 26, Palma de Mallorca, 2000, pp. 145-159. 
disposiciones relevantes, algunas de las cuales constituyeron una novedad en aquellos tiempos, y otras se inscribieron como comenta Álvaro Santamaría, en el área de normativa de influencia de la Carta de Población otorgada en noviembre del 1149 a la ciudad de Tortosa. ${ }^{5}$

A través de la Carta de Franquesa de Mallorca, Jaime I iba a proporcionar importantes libertades jurídicas, privilegios y un conjunto de exenciones fiscales a aquellos cristianos que decidiesen repoblar las Islas Baleares. Los nuevos habitantes de las islas tenían el derecho de transmitir libremente su patrimonio en las condiciones establecidas en los documentos, incluidos los condenados a muerte y los que no tenían descendencia. Únicamente, no podían vender las propiedades otorgadas por el monarca a los nobles y a las personas religiosas (exceptis militibus et personis religiosis), en un intento de evitar que los bienes de realengo pudiesen incrementar el patrimonio señorial y eclesiástico.

Asimismo, los repobladores podían aprovechar los bienes públicos para su propio uso, sin necesidad de requerir ningún tipo de licencia ni pagar gabelas al monarca, como dueño directo. La Carta identifica los bienes públicos en contraposición a los privados, definiendo así el primer mapa de uso de suelos de las Islas. En la categoría de bienes públicos se encontraban los bosques, los pastos y las aguas terrestres y marítimas. De esta forma, los habitantes de las islas podían recolectar frutos, cazar, pescar y recoger la leña en estos espacios. La monarquía sólo se reservó el uso de las aguas estancadas, es decir, las salinas y las albuferas, para disfrute propio, como la de Alcudia.

La Carta también eliminó algunos de los malos usos como la questia, el pesaje, la hueste y la cabalgada o el herbaje, que solían gravar a los campesinos, especialmente en la Cataluña Vieja. A los pobladores que acudieran a las Islas Baleares y que tuvieran posesiones agrícolas, no se les exigirían estos derechos y servicios pecuniarios.

Los nuevos ocupantes también obtuvieron una serie de ventajas fiscales en el ámbito comercial. Se les eximió de pagar diversas tasas de circulación de mercancías entre las Islas Baleares y los territorios de la Corona de Aragón, como la lezda, el peaje, el portaje, el mesuraje y el ribaje. No obstante, como comenta José Francisco López, ${ }^{6}$ esta exención parece que sólo fue aplicada a los habitan-

5 SANTAMARÍA ARÁNDEZ, A.: Ejecutoria del Reino de Mallorca (1230-1343), Ajuntament de Palma, Palma de Mallorca, 1990, pp. 31-32 y notas 6 y 7. La mayor parte de libertades, franquicias y costumbres que figuran en la carta mallorquina, también aparecerán en la carta de Ibiza, otorgada en 1236, como comenta BELENGUER I CEBRIÀ, E., Jaume I i el seu regnat, Pagés editors, Lleida, 2007, p. 101.

6 LOPEZ BONET, J. F: «Para una historia fiscal de la Mallorca cristiana (siglos XIII-XV)», Anuario de Estudios Medievales, CSIC, 38/1, enero-junio 2008, p. 113, nota 16. 
tes de las ciudades, y no se hizo extensión a los foráneos hasta 1345, en época de Pedro IV. Esta medida no supuso una limitación apreciable de los intercambios comerciales entre las Islas y la Corona de Aragón; sólo podía determinar que los mercaderes prefirieran establecerse y residir en el ámbito urbano por las ventajas que conllevaba, en lugar de hacerlo en el ámbito foráneo. Además, la Carta de Franquesa favorecía sus intereses por otros motivos. Se establecía el libre comercio con los territorios aragoneses, incluidos los que se integrasen en el futuro, y se protegían sus actividades ante determinadas situaciones, como el naufragio.

La Carta también incluyó apartados relativos a la administración de la justicia. El monarca mostraba así una preocupación para que la justicia fuera eficaz y objetiva en el Reino de Mallorca y que regulase la convivencia entre los nuevos habitantes de las Islas. Este hecho se percibe en la propia carta, donde hay un predominio de los aspectos judiciales.

La justicia debía posibilitar que los habitantes de las Islas pudieran defenderse en los tribunales, con independencia de su posición social y riqueza poseída, y garantizar la salvaguardia de la convivencia social y el mantenimiento del orden público mediante su impartición. Según lo promulgado por Jaime I, tenía que ser pública y gratuita. Los oficiales reales no podían cobrar tasas judiciales a los pobladores, y debían celebrar las audiencias en lugares públicos, estando abiertas a toda la comunidad. Tampoco podían entrar en domicilios privados, sin que estuvieran presentes dos representantes de la comunidad o cuatro prohombres. El batlle y el veguer eran los responsables de impartir justicia a los habitantes, como representantes del soberano en el Reino de Mallorca, y en calidad de jueces. El primero actuaba en temas civiles y patrimoniales, mientras que el segundo debía hacer justicia en materia criminal.

Aún así, como comenta Pau Cateura, la justicia aún sería inaccesible para las clases sociales mallorquinas más desfavorecidas durante las primeras décadas de dominio cristiano. La Carta de Franquesa no incluyó procedimientos para habilitar abogados y procuradores de pobres, por lo los mallorquines podían acudir a la justicia, pero serían ellos quienes deberían plantear la defensa judicial. ${ }^{7}$

La Carta tampoco definió el alcance de la justicia soberana en el Reino de Mallorca, así como la jurisdicción que debía competer a los magnates en sus porciones señoriales. Este aspecto era esencial para resolver los posibles litigios suscitados entre los habitantes presentes en las áreas regidas por el monarca, y en aquellos señoríos jurisdiccionales rurales y urbanos que se habían definido tras el repartimiento. Después de complicadas negociaciones, Jaime I llegó a un

CATEURA BENNASSER, P., Mallorca en el segle XIII, El Tall Editorial, Conèixer Mallorca, 1, Palma de Mallorca, 1997, pp. 29-30. 
acuerdo con los nobles porcioneros en abril de 1231 que le garantizaba el control de la alta justicia y la asunción del mero y mixto imperio en materia civil y criminal. La nobleza asumía la competencia de la baja justicia en sus respectivas jurisdicciones, entendida como delitos menores que comportaban penas pecuniarias. Se concretaba así una de las cuestiones que debía definir la identidad judicial del Reino de Mallorca.

Sin duda, el acuerdo de 1231 fue ventajoso para el soberano, ya que no siempre acabaría reteniendo la alta justicia y el mero y mixto imperio en otras áreas conquistadas, como ha puesto de manifiesto Álvaro Santamaría. ${ }^{8}$ Además, la monarquía también tenía la capacidad para conferir los derechos de ambos monopolios a la nobleza, cuando lo estimase oportuno, a cambio de dinero o servicios prestados. ${ }^{9}$

La Carta apenas comenta aspectos políticos, pero aquellos que se incluyeron, tuvieron una gran importancia por su relevancia. Especialmente significativo es el apartado 37 en el que se señalaba que el soberano se comprometía a que el Reino de Mallorca permaneciese unido a la Corona de Aragón, por lo que no se donaría o permutaría a otras personas, tanto religiosas como militares. Además, Jaime I también protegería a los pobladores de las Islas en calidad de súbditos leales y fieles a la Corona. Con estas disposiciones, definía el carácter patrimonial del Reino de Mallorca, a la vez que garantizaba su defensa como parte indisociable de la Corona de Aragón.

Si bien Jaime I no pudo cumplir con el compromiso de no permutar el territorio, ya que apenas un año y medio después tuvo que ceder la administración del Reino de Mallorca a Pedro de Portugal a cambio del Condado de Urgel por cuestiones de política interna, no hay duda de que la Carta de Franquesa marcaba la línea política que los sucesores del monarca aragonés debían seguir respecto a este territorio. Jaime I volvió a recuperar nuevamente el Reino de Mallorca en 1244, y aunque hubo un breve período en que debió confiar nuevamente el gobierno de este territorio a Pedro de Portugal en 1254, lo mantuvo unido a la Corona hasta su muerte, en 1276.

8 Véase SANTAMARÍA ARÁNDEZ, A., Ejecutoria del Reino de Mallorca (1230-1343), Ajuntament de Palma, Palma de Mallorca, 1990, pp. 524-525, donde señala que algunos señores beneficiarios entre los que figura Nuño Sans, Berenguer, obispo de Barcelona, y el caballero Ramón Berenguer de Ager, que participaron en la conquista de Mallorca, asumieron en algunos lugares de Valencia en mero y mixto imperio, tras la concesión de Jaime I.

9 CATEURA BENNÁSSER, P., «La administración de justicia en la ciudad de Mallorca en la época de Pedro el Ceremonioso» en la España Medieval, 7, Universidad Complutense, Madrid, 1985, p. 1318, señala que Jaime III confirió el mero y mixto imperio sobre los habitantes de la localidad de Bunyola a su lugarteniente Arnaldo de Cardellach en pago por sus servicios. 
Con la Carta de Franquesa, Jaime I quiso evidenciar la importancia que concedía al nuevo reino como lugar de repoblación cristiana, mediante la eliminación de la mayoría de las exenciones señoriales, gabelas arbitrarias y malos usos que podían dificultar la venida de los pobladores, no sólo en la isla de Mallorca, sino también en los que aún debían ser conquistados como Ibiza y Menorca. La Carta constituye un documento de atracción de la población cristiana, definiendo una justicia que favoreciera a todos los habitantes por igual, y concediendo franquicias y condiciones ventajosas en ámbitos como el tráfico comercial, las propiedades y el uso de bienes públicos. Asimismo, regulaba los derechos y deberes de los pobladores.

Para el soberano, las Islas Baleares tenían una importancia estratégica, ya que aunque no constituían un espacio directo de frontera con los musulmanes como sucedía en la mayoría de territorios de la Corona de Aragón, se encontraban en una posición geográfica privilegiada dentro del Mediterráneo Occidental. La ocupación de las Islas Baleares favorecía el control de las rutas marítimas que iban desde la Península Ibérica a la Península Italiana y al Mediterráneo Oriental. Por este motivo, la Carta de Franquesa de 1230 otorgada a los habitantes del Reino de Mallorca refleja un paso más en la mejora de las condiciones jurídicas de los pobladores que se desplazaban a los nuevos dominios aragoneses, al menos si se compara con los primeros actos jurídicos otorgados por los soberanos aragoneses en el siglo XII.

Jaime I siguió estimulando la repoblación en el Reino de Mallorca con otras medidas de amplio calado, aunque concretadas a mediados del siglo XIII. En la década de los años 30, el soberano apenas legisló sobre las Islas Baleares, inmerso en la reconquista de nuevos territorios como el Reino de Valencia, y habiendo confiado el gobierno insular a Pedro de Portugal. Volvió a reemprender la actividad legislativa en 1242, y entre sus iniciativas se encuentra una particularmente interesante: la que especificaba que aquellos que se instalaran en Mallorca con ánimo de poblarla, serían liberados de cualquier modalidad de redención personal que pudieran tener con los señores feudales de Cataluña. Sin duda, esta ordenanza debió acrecentar la llegada de nuevos habitantes a la isla.

\subsection{La institución del municipio en el Reino de Mallorca: la identidad cívica}

El monarca había organizado la repoblación y la incipiente administración Real del Reino en los primeros años de dominio cristiano en Mallorca, pero aún faltaba dotar de un marco institucional a la Universidad de Mallorca, entendida como el cuerpo jurídico representativo de los habitantes de la Ciudad y el Reino de Mallorca. 
Por esta razón, Jaime I llevó a cabo el proceso de creación de una organización municipal en Mallorca mediante la promulgación de una carta fundacional en Valencia en 1249, con dos décadas de retraso como consecuencia de los avatares políticos de la Corona de Aragón. La Carta de Franquesa tampoco define la identidad municipal del Reino de Mallorca, aunque ciertamente se constituyó en el primer punto de partida jurídico, a la vez que concretaba algunas de las funciones de los prohombres como miembros destacados de la comunidad. No obstante, no será hasta mediados del siglo XIII, cuando el monarca aragonés instituya el municipio orgánico en Mallorca, que se debe enmarcar en una política municipalista mucho más amplia que incluyó las principales ciudades de la Corona de Aragón.

La constitución del municipio tuvo importantes consecuencias, ya que permitió a los mallorquines tener una cierta autonomía a la hora de poder gestionar la isla, entendida inicialmente como una demarcación municipal única. La Universidad de Mallorca pudo regular y llevar a cabo la política territorial, y lo que es más importante, disponer de recursos para financiarla.

Jaime I instituyó el sistema municipal en el Reino de Mallorca el 7 de julio de 1249. Según la carta fundacional, creaba una comisión ejecutiva conformada por seis Jurados, uno de los cuales debía ser perceptivamente del estamento de los caballeros, como representante de la jerarquía superior de la sociedad de la isla, según una breve cláusula añadida al final del escrito. A efectos prácticos, se llegó gradualmente a un consenso dentro de la propia Universidad de Mallorca para que los cargos estuvieran conformados por dos ciudadanos, dos comerciales, un menestral y un caballero.

Como magistrados municipales, los seis Jurados como magistrados municipales tenían la función de gobernar, administrar y regir la isla para provecho del monarca y de la universidad (gubernare vel administrare et regere totam insulam ad fidelitatem et comodum nostrum et comune comodum universitatis). No obstante, no tenían capacidad para asumir jurisdicciones, lo que indudablemente constituía una limitación notable a su labor.

El cargo tenía una duración anual. Los Jurados no podían ser reelegidos. La magistratura municipal se renovaba habitualmente el día de Navidad, en presencia del Batlle Real como representante del monarca, si este último se encontraba ausente. La renovación de los cargos se hacía a través del sistema de cooptación. Mediante este sistema, los Jurados salientes escogían libremente a los entrantes entre aquellos prohombres que considerasen más capacitados y honrados para gestionar las tareas municipales. La monarquía pretendía que se constituyesen equipos de Jurados que desempeñasen la magistratura con cierta continuidad y garantizasen una notable eficacia administrativa durante su año de mandato. Con la renovación anual, también se evitaba su perpetuidad en el cargo. 
Los nuevos Jurados debían jurar el cargo y comprometerse a gobernar la comunidad de forma honrada y con lealtad al soberano del Reino de Mallorca. La magistratura no estaba remunerada y además era irrenunciable. Se obligaba al designado a aceptar el cargo y a ocuparse de la gestión municipal en beneficio de los habitantes de la isla. Por su parte, el monarca garantizaba su apoyo a las decisiones tomadas por los Jurados dentro de sus competencias municipales, aunque se reservaba el derecho a destituir a los Jurados o a suspender el sistema municipal cuando lo considerase de forma oportuna.

Los Jurados tenían plenas atribuciones en asuntos económicos, sociales y recaudatorios de alcance insular, sin poder extenderlas a otras islas. Entre otros aspectos, debían decidir sobre aquellas cuestiones que afectaban a las obras públicas, la sanidad, las defensas, el tráfico comercial o los servicios municipales.

En virtud de la Carta Municipal de 1249, también se creaba un Consejo Ejecutivo encargado de asesorar a los Jurados en la toma de decisiones. Los Jurados designaban libremente a los miembros de este Consejo o Consell General, llamados Consejeros, sin limitación de número, ni condición social. Los Consejeros cumplían algunas funciones en el área de sus competencias municipales y aconsejaban a los Jurados a la hora de escoger a sus sucesores.

Jaime I creaba así un sistema municipal que se configuró no sólo en Mallorca, sino que se extendería con posterioridad a las otras islas, determinado la identidad municipal del Reino de Mallorca. ${ }^{10}$ Sin embargo, el sistema tenía algunas carencias importantes que se fueron revelando con el tiempo, y que conviene destacar: La cooptación no impedía que se pudieran constituir grupos de Jurados que se fueran alternando en el poder y que gobernasen en beneficio suyo y de los que debían sucederles. A lo largo de la Baja Edad Media, los gober-

${ }^{10}$ En 1299, Jaime II concedió a los habitantes de Eivissa y Formentera la función de regir y ordenar sus propios asuntos como sanidad, abastecimiento y obras para la defensa entre otros. Los alcaldes de los tres coseñores debían elegir tres prohombres de la tierra a modo de Jurados, y estos a su vez, diez hombres buenos o consellers como asesores que integraban el Consell General d'Eivissa. Véase, FERRER ABARZUZA, A., «La Dinastía de Mallorca-Rosellón (1276-1343) en Historia de las Islas Baleares, Vol. VII, Editorial El Mundo, Palma de Mallorca, 2007, pp. 232-233». En cuanto a Menorca, el rey mallorquín ordenó la elaboración de una Carta de Población o franquicia en 1301 que permitió dotar a la isla de una organización municipal. El número de Jurados era 4, uno de los cuales debía ser necesariamente un miembro del brazo militar. Los Jurados también podían escoger 10 consejeros que integraban un Consejo General. De esta forma, como comenta CATEURA BENNÁSSER, P.; «El rey burlado: Deuda Pública y Fiscalidad en el Reino de Mallorca (siglo XV)» en Anuario de Estudios Medievales, CSIC, 38/1, enero-junio 2008, p. 186, al filo del 1400, el Reino de Mallorca quedaba configurado en tres organismos: El Gran i General Consell de Mallorca, donde se integraba el brazo de los foráneos; el Consell General de Menorca y el Consell General d'Eivissa. 
nantes mallorquines irían modificando el sistema de elección en la búsqueda de un régimen adecuado de designación de cargos municipales que impidiera las luchas políticas internas y la corrupción, y garantizase la eficacia del sistema en beneficio de la comunidad.

Además, el municipio diseñado por Jaime I no tenía una autonomía real, por cuanto sus actuaciones estaban determinadas por la voluntad de la monarquía. No olvidemos que la Corona tenía la prerrogativa de reemplazar a los Jurados o suspender el funcionamiento de la organización municipal. De hecho, dos reyes tan distintos como Jaime II de Mallorca y Alfonso III de Aragón, este último durante el período de dominio aragonés de las Islas Baleares entre 1285 y 1298, convirtieron el municipio mallorquín en un instrumento al servicio de la Corona. Para ello, introdujeron nuevas reformas, llegando incluso a modificar la estructura municipal en el caso del soberano aragonés, ${ }^{11}$ a fin de subordinar la institución a la monarquía.

La reforma del municipio en Mallorca no haría sino consolidar la importancia de la Ciutat de Mallorques que iba creciendo gradualmente y demográficamente desde la ocupación cristiana. A mediados del siglo XIII, la antigua capital musulmana era la única urbe de importancia en la isla, hecho que contrastaba con las pequeñas parroquias presentes en la Part Forana. Esta dicotomía Gran Ciutat-Part Forana tuvo sus consecuencias en el sistema municipal. El área insular quedaba como término municipal de la ciudad, y los cargos municipales eran elegidos entre los habitantes de la capital mallorquina por costumbre. De esta forma, la Ciutat de Mallorques extendía su jurisdicción sobre el resto del área insular.

Fueron los habitantes de la Part Forana de Mallorca, quienes propiciaron la última gran reforma de las instituciones municipales, ya en época del rey Sancho de Mallorca. Exigieron su participación en la toma de decisiones municipales, tratando de modificar la situación creada en 1249. Los foráneos se habían agrupado en los nuevos municipios mallorquines fundados a raíz de las Ordinacions de Jaime II en 1300 y respondían a una nueva realidad como era la consolida-

${ }^{11}$ Alfonso III de Aragón instauró un sistema municipalista llamado Consolat, por el cual un Procurador Real se encargaría de designar a los nuevos Jurados mallorquines. Hasta entonces, la elección de los Jurados se hacía por el sistema de cooptación. Durante la segunda etapa de gobierno entre 1298 y 1311, Jaime II de Mallorca restauró la cooptación, pero su reposición se hizo según criterios claramente intervencionistas, ya que la designación de los Jurados debía ser ratificada por el soberano o en su defecto por el Lugarteniente Real. Véase, TUDELA VILLALONGA, L., «La Dinastía de Mallorca-Rosellón (1276-1343)» en La Historia de las Islas Baleares, Vol. VII, Editorial El Mundo, Palma de Mallorca, 2007, pp. 58 y 118 
ción de la concentración urbana en el interior de la isla. ${ }^{12}$ Las parroquias rurales habían crecido de forma notable tras la llegada de nuevos repobladores.

La población foránea tenía unos intereses muy diferentes a los residentes en Ciutat de Mallorques, y sus peticiones no siempre eran atendidas por los Jurados y los Consejeros municipales, quienes primaban las cuestiones relativas a la capital mallorquina ante la administración Real. No obstante, los foráneos no estaban dispuestos a que la situación siguiera así. Ellos también contribuían con sus impuestos a mejorar las infraestructuras. Era lógico, por tanto, que reivindicasen su intervención en los principales asuntos municipales. No obstante, los Jurados no estaban dispuestos a ceder su poder a fin de seguir rigiendo y administrando en toda la isla.

En un ambiente de gran tensión y confrontación entre Jurados y foráneos, el rey Sancho intervino para resolver la cuestión. La idea del monarca era muy simple: reducir el poder de la Juraría y del Consell municipal, aprovechando las quejas de los colectivos agrarios. En diciembre de 1313, Sancho había devuelto la autonomía de la gestión municipal a la Universidad de Mallorca, después de que Jaime II la hubiera reducido de forma considerable con su política intervencionista. Sin embargo, su decisión, realizada a petición de los Jurados, también suponía un aumento de la fortaleza del Municipio mallorquín frente a la Corona en cuestiones políticas y económicas, y este hecho no pasaba desapercibido a Sancho.

El monarca mallorquín promulgó finalmente tres sentencias entre el 19 de junio y el 23 de julio de 1315, por las que establecía un nuevo sistema municipal. En razón de estas sentencias, la Universidad de Mallorca quedaba dividida en dos nuevas instituciones. Por una parte, se mantenía la Universitat de la Ciutat, representada por los seis jurados renovados anualmente y por el Consell de la Ciutat, organismo conformado por los Consejeros de las diferentes clases sociales mallorquinas que eran competentes en asuntos de la ciudad y su término municipal.

Por otra, se creaba la Universidad Foránea representada por diez síndicos que conformaban la comisión ejecutiva, así como el Consell del Sindicat Forà, integrado por los representantes de cada villa, a excepción de la capital mallorquina, y que podían actuar en aquellas cuestiones comunes de la Part Forana. Asimismo, también se establecían los Consells de les Viles, en los que representantes locales de cada una de las 33 parroquias rurales constituidas en Mallorca tenían competencias en sus respectivos términos municipales.

${ }^{12}$ Respecto a la creación de estos pueblos y la forma de planificación, es conveniente consultar, ANDREU GALMÉS, J., «Lurbanisme planificat segons les ordinacions de Jaume II» en Jaume II i les Ordinacions de l'any 1300, Consell Insular de Mallorca, Palma de Mallorca, 2002, pp. 165-177; SANTAMARÍA ARÁNDEZ, A., Ejecutoria del Reino de Mallorca (1230-1343), Ajuntament de Palma, Palma de Mallorca, 1990, pp. 475-479. 
Como colofón a este nuevo régimen municipal, se constituía El Gran i General Consell de Mallorca, organismo con capacidad de decisión en aquellos asuntos comunitarios que afectasen tanto a la capital como a las villas rurales. Este Consejo General estaba constituido por consejeros del Consell de la Ciutat y del Consell del Sindicat Forà en una proporción de 2/3 miembros de ciudadanos de la capital y $1 / 3$ de foráneos.

La Juraría perdía bastantes atribuciones con la aparición de las nuevas instituciones. Hasta entonces, los Jurados podrían designar de forma libre y en el número que estimasen oportuno a los Consejeros que debían formar parte del Consejo Ejecutivo. Con la reforma de 1315, sólo podrían nombrar a los Consejeros de la Ciudad de Mallorques, y, únicamente, hasta cubrir las 2/3 partes que le correspondían en El Gran i General Consell de Mallorca, según la proporción establecida en las sentencias.

Sancho instituyó así un nuevo sistema municipal para la isla de Mallorca. Además, se había convertido en el gran triunfador del conflicto suscitado entre los Jurados y los foráneos, debido a su gran habilidad política. Con su iniciativa, había debilitado al municipio mallorquín ante la monarquía. Había atendido las reclamaciones de los pobladores de las villas, nuevo grupo con importantes intereses agrarios y que se había incorporado a la dinámica económica mallorquina desde principios de siglo. Gracias al rey, los foráneos tenían nuevas instituciones donde resolver sus problemas municipales. Sancho y sus sucesores podría apoyarse en ellos cuando las circunstancias políticas así lo requiriesen.

Asimismo, Sancho había conseguido mantener el espíritu de la Carta Fundacional de 1249 , por la que los Jurados seguían eligiendo a los Consejeros. La Universidad de Mallorca había recuperado nuevamente la semiautonomía municipal, una condición que también disfrutarían las Universidades de Menorca e Ibiza. Además, los habitantes de Ciutat de Mallorques aún mantenían la mayoría de representantes en El Gran i General Consell de Mallorca, y los foráneos mallorquines habían conseguido representatividad. Por este motivo, los habitantes de las islas se sintieron identificados con estas instituciones municipales que persistirían a lo largo de la Edad Media. De esta forma, la identidad municipal del Reino de Mallorca quedaba perfilada a instancias de la Corona. ${ }^{13}$

${ }^{13}$ En el siglo XV se produjeron algunas modificaciones en cuanto al número y composición de miembros de la institución del Gran i General Consell de Mallorca, como señalan PASCUAL RAMOS, E., «Consideraciones sobre la revuelta foránea de Mallorca (1450-1452) y las insurrecciones campesinas en la Península durante la segunda mitad del siglo XV» en Mayurqa, 28, Palma de Mallorca, 2002, p. 279; URGELL HERNÁNDEZ, R., Mallorca en el segle XV, El Tall Editorial, Conèixer Mallorca, 7, Palma de Mallorca, 2000, pp. 9-11. 


\section{LA IDENTIDAD NACIONAL Y TERRITORIAL DEL REINO DE MALLORCA}

La creación del marco institucional en las Islas Baleares favoreció un gradual desarrollo de las estructuras político-administrativas en el territorio balear a lo largo del siglo XIII.

La organización institucional balear ya estaba plenamente operativa cuando Jaime I decidió escindir a su muerte la Confederación Catalano-Aragonesa en dos Estados soberanos, la Corona de Aragón y el Reino de Mallorca. Según el testamento fechado en 1262, Jaime I otorgaba a Pedro, su primogénito, el principado de Cataluña y los Reinos de Valencia y Aragón, tres zonas de notable extensión y fronterizas. Jaime, el hijo menor, futuro Jaime II, recibía un conjunto de territorios muy dispersos, conformado por las islas de Ibiza y Mallorca en el archipiélago balear, y por los condados del Rosellón y la Cerdaña, los territorios del Capcir y Vallespir, el señorío de Montpellier y el vizcondado de Carlades y Omelades en los Pirineos y el sur de Francia, área que apenas superaba los 5.000 kilómetros cuadrados. Esta decisión de Jaime I que ha extrañado a la gran mayoría de historiadores, debe entenderse a partir de una antigua costumbre medieval, y que consistía en entender los territorios como un concepto patrimonial, como una especie de propiedad privada que podía ser enajenada y dividida entre los herederos, siempre que estuviera conforme con el derecho sucesorio regulador.

En 1276, el Reino de Mallorca iniciaba así su camino como un Estado plenamente independiente y con una nueva dinastía. Sin embargo, el nuevo Estado era débil desde un punto de vista político. Jaime II debía gobernar sobre una serie de territorios de escasa extensión que tenían unas estructuras administrativas, sociales, e intereses económicos muy diferentes, situados en ámbitos geográficos heterogéneos: insular en un caso y territorial en los otros. Así, Mallorca e Ibiza, y posteriormente Menorca, se encontraban en un período de repoblación y consolidación del dominio cristiano, con la instauración de un incipiente feudalismo. La burguesía comercial se había convertido en el colectivo más influyente del archipiélago balear, ya que generaba la mayor parte de la riqueza que afluía al territorio. Las Islas Baleares ocupaban una posición ideal en el Mediterráneo Occidental, equidistante respecto a los principales centros económicos de la zona. Actuaban como privilegiados lugares de tránsito de las mercaderías que viajaban a Oriente y al Atlántico septentrional. Los mercaderes insulares vendían los bienes, materias primas y productos que adquirían en otros enclaves y habían comenzado a establecer redes comerciales con otros territorios, principalmente con el Norte de África, la Corona de Aragón y la Península Italiana. 
En cambio, los condados del Rosellón y la Cerdaña, relativamente poblados, eran zonas muy feudalizadas en las que predominaba la aristocracia, relativamente poblados, y cuya base económica era la tierra. Además, mantenían una estrecha ligazón con Cataluña. Por su parte, el señorío de Montpellier era esencialmente urbano. Constaba de una gran ciudad, rica y próspera, y de un territorio rural circundante. Montpellier también se encontraba en una posición geográfica privilegiada, punto de articulación de las vías terrestres que se dirigían a Francia, y especialmente a las Ferias de Champaña, las más importantes de Occidente. Sus intereses estaban en el Norte de Europa, y, en menor medida en el sur. Sus habitantes hablaban occitano a diferencia de los otros territorios mallorquines que estaban inmersos en el área lingüística catalana. El patriciado urbano de Montpellier era la clase social más importante del señorío, tras especializarse en la producción y la venta de pañería de notable calidad.

Cada uno de estos territorios disponía de sus propias instituciones, por encima de las cuales se encontraba únicamente la monarquía, quien era la que garantizaba la unidad del nuevo Estado. Algunas de las estructuras ya estaban plenamente consolidadas como ocurría en los territorios ultrapirenaicos, mientras que otras se hallaban en plena etapa de creación como era el caso de las Islas Baleares.

Distintas clases sociales gobernaban en territorios del Reino de Mallorca, defendiendo diferentes líneas de actuación económica en beneficio de sus intereses y de los lugares a los que representaban. La burguesía comercial balear era partidaria de la libre circulación de bienes, posición que no era compartida por los terratenientes y los gremios artesanales de los territorios ultrapirenaicos, más interesados en una política que protegiera los bienes de consumo y los productos elaborados. Este contraste de intereses también dificultaba la toma de decisiones por parte de los soberanos mallorquines. Cualquier iniciativa que la monarquía emprendiese en beneficio de una clase social o un área en concreto, podía perjudicar a las otras.

Esta heterogeneidad geográfica, política, económica, institucional y social no favorecía la constitución de una identidad nacional en el Reino de Mallorca. El carácter artificial del Estado creado por Jaime I propiciaba que los habitantes del Reino de Mallorca no tuviesen un sentimiento nacional, ligado al sentido de pertenencia al nuevo territorio. Como explica Gabriel Ensenyat, la gran mayoría de pobladores cristianos no tuvo ningún tipo de conciencia nacional diferente al resto de territorios catalanes de la Corona de Aragón. Se seguían identificando como catalanes, cuando hacían referencia a su origen, y sólo en escasas ocasiones se llamaban así mismo catalanes de Mallorca. Mantenían las costumbres, antiguas tradiciones y aspectos culturales originarios de la Corona de Aragón. De ahí que 
la falta de identidad nacional tampoco vino acompañada de una identificación de los habitantes mallorquines con el Reino como ámbito territorial de identidad. ${ }^{14}$

Todo este conjunto de circunstancias hacía que el Reino de Mallorca fuera un Estado muy vulnerable frente a las presiones de los grupos sociales más influyentes de cada territorio, y especialmente ante las naciones con importantes intereses económicos y políticos en el área mediterránea occidental, como la Corona de Aragón, la República de Génova y el Reino de Francia. La Corona mallorquina no sólo debía mantener una estrategia que beneficiase al conjunto de sus fuerzas sociales, sino que pudiera hacer frente a las amenazas externas. El testamento de Jaime I tampoco favorecía este propósito. El Reino de Mallorca tenía unos recursos económicos y militares escasos, un problema grave en caso de bloqueo o agresión por otro Estado. Además, sus territorios estaban dispersos como ya se ha comentado, circunstancia que dificultaba la movilización de sus fuerzas desde un territorio a otro.

El hecho de que un porcentaje significativo de habitantes del Reino de Mallorca tampoco se sintiera identificado con la idea de formar parte de un nuevo territorio, dificultaba aún más la labor de la Corona mallorquina de resistir mejor los embates diplomáticos y militares de otros Estados más poderosos. Jaime II pudo constatar este problema en los primeros años de reinado. En 1279, Pedro III de Aragón obligó a su hermano Jaime a firmar un acuerdo de infeudación en Perpiñán, por el que este último reconocía «de buena fe» y «voluntad espontánea» que administraba los distritos territoriales del Reino de Mallorca no como soberano, sino como su vasallo. El Tratado de Perpiñán supondría un cambio de la situación jurídica del Reino de Mallorca: Como tal, dejaba de existir como un Estado plenamente independiente y quedaba reducido a un conjunto de territorios con una amplia autonomía política en el seno de la Corona de Aragón. Además, el monarca mallorquín como feudatario del soberano aragonés estaba obligado a acudir a las Cortes Generales de Cataluña, cuando fuese necesario.

Las clases sociales mallorquinas evidenciaron una actitud diferente tras la modificación de la situación jurídica del Reino de Mallorca. Algunas manifestaron su desacuerdo. La aristocracia laica y religiosa temía perder los privilegios y las influencias sobre el monarca mallorquín, ahora que la Corona de Aragón podía dictaminar la política en el Reino de Mallorca. En los condados pirenaicos, había una creencia generalizada entre los gremios artesanales de que el acuerdo favorecería una entrada masiva de artículos manufacturados catalanes, lo que iba en perjuicio de la producción local.

${ }^{14}$ ENSENYAT PUjOL, G., «L' Herència Política», en Diario de Mallorca, 2 de Febrer de 2008, p. 15. 
En cambio, amplios sectores sociales de las Islas Baleares, y especialmente la burguesía comercial, poderosa desde un punto de punto de vista político y económico, valoraron de forma positiva que la Corona de Aragón tutelase el Reino de Mallorca, y por tanto que este último continuase unido al primero. El comercio exterior balear confiaba en que la Corona de Aragón, siendo gran potencia naval, protegería sus intereses comerciales en los mercados mediterráneos que ya estaban frecuentando. En su opinión, tendrían más facilidades para negociar en las áreas de la Corona de Aragón, y en aquellas donde los catalanes apenas tenían competencia.

La realidad del Tratado de Perpiñán puso de manifiesto la existencia de actitudes y comportamientos muy diferentes en el seno del Reino de Mallorca ante un mismo problema político. Un número significativo de habitantes insulares no era partidario de que el Reino de Mallorca se mantuviera independiente y separado del resto de territorios de la Corona de Aragón, especialmente los residentes en las principales urbes. Los intereses económicos estaban por encima de su posible identificación y pertenencia al nuevo Estado surgido por la voluntad de Jaime I. Esta forma de entender la política exterior se fue repitiendo en las diferentes ocasiones en que la Corona de Aragón actuó contra la Corona mallorquina. Se constató este hecho en un nuevo conflicto entre Jaime II y Pedro III de Aragón que se enmarca en las Vísperas Sicilianas. El intento del monarca mallorquín de buscar apoyos en otros Estados, y más concretamente en el Reino de Francia, para tratar de limitar la capacidad de mediatización política que la Corona de Aragón ejercía sobre el Reino de Mallorca, tuvo una respuesta rápida y contundente por parte de Pedro III. El rey aragonés ocupó algunas ciudades del Rosellón, entre las que estaba Perpiñán, la capital del reino mallorquín, en 1285, y meses después, ordenó a su hijo el infante Alfonso, futuro Alfonso III, que invadiera y recuperara las Islas Baleares.

Pedro III no pudo mantener la capital del reino durante mucho tiempo. La invasión francesa en Cataluña, el temor a una intervención de los franceses en la zona y la resistencia de la aristocracia laica y religiosa del Rosellón impidieron una ocupación permanente del territorio. Los esfuerzos del colectivo mercantil presente en Cerdaña y Rosellón por favorecer la anexión de los condados a la Corona de Aragón resultaron inútiles. Por el contrario, la Corona de Aragón retuvo las Islas Baleares durante trece años. La mayoría de habitantes de Mallorca e Ibiza, con la burguesía comercial insular al frente, apenas ejerció resistencia a la monarquía aragonesa. Estaban más identificados con la Corona aragonesa por cuestiones económicas que con la Corte de Perpiñán. Nueve años después de la creación del Reino de Mallorca, la población balear seguía sin tener un sentimiento nacional, de pertenencia al nuevo Estado creado en 1276. 
Con estas premisas, el Reino de Mallorca tenía pocas posibilidades de supervivencia política. En 1343 se volvió a repetir el mismo proceso con diferentes personajes. Pedro IV de Aragón ocupó las Islas Baleares con mucha facilidad. En cambio, acabó incorporando los condados ultrapirenaicos en 1344 con gran dificultad tras dos duras campañas contra los partidarios de Jaime III de Mallorca; en su mayoría nobles que no querían perder los privilegios que disfrutaban. Montpellier, el único territorio en que no predominaba la lengua catalana, fue vendido por Jaime III a los franceses en 1349, en el transcurso de la última tentativa de recuperación de los territorios ocupados por Pedro IV por parte del noble mallorquín.

La anexión definitiva del Reino de Mallorca por Pedro IV vino acompañada de su incorporación a las instituciones catalanas, y la gradual identificación de los mallorquines con el Estado y los territorios que formaban parte de la Corona de Aragón. La monarquía aragonesa también favoreció este hecho. Pedro IV definió a los habitantes de las Islas Baleares como catalanes en virtud de una pragmática promulgada en Sant Feliu de Guíxols en 1365 (los mallorquins siau hahuts e reputats per catalans...). ${ }^{15}$ Además, los mallorquines mantuvieron su organización municipal y asistieron a las Cortes Generales de Cataluña, siendo representados por síndicos. Sin embargo, no tuvieron Cortes separadas y formaron parte del brazo respectivo del Principado de Cataluña, estando sometidos a los Usos y Constituciones de Cataluña.

\section{LA IDENTIDAD EDILICIA DEL ÁMBITO URBANO MALLORQUÍN}

Jaime II de Mallorca fue el soberano que mejor entendió la necesidad de constituir una identidad nacional para el Reino de Mallorca. En cierta medida, era consecuencia de algunos de los acontecimientos que había vivido en política exterior, como la pérdida de las Islas Baleares durante trece años, la falta de respuesta de los insulares a la ocupación realizada por otro Estado, y la desmesurada ambición demostrada por determinadas naciones a la hora de mediatizar las actuaciones políticas del Reino de Mallorca.

Tras la recuperación de las Islas Baleares en 1298, Jaime II consideraba que era el momento adecuado para poner en marcha un conjunto de actuaciones que debían generar riqueza en el conjunto de los territorios que conformaban el Reino de Mallorca. Durante dos décadas, la política exterior había impedi-

\footnotetext{
15 Se trata del Capítulo promulgado por Pedro IV el 22 de julio de 1365 incluido en el ARM, Llibre de Sant Pere, f. 162 v. No obstante, para algunos investigadores como PLANAS ROSSELLÓ, A., «La sucesión intestada de los impúberes y la supuesta aplicación de las Constituciones de Cataluña en Mallorca. Reflexiones en torno a un pleito en 1374-1378», Ius Fugit, Revista de Estudios Histórico-Jurídicos de la Corona de Aragón, Vol. 8-9, Institución «Fernando el Católico», Zaragoza, 1999-2000, p. 115, se trata de una falsificación.
} 
do desarrollar políticas de gobierno. Ahora, el soberano reinaba nuevamente sobre todo el legado de su padre, y quería resolver los numerosos problemas internos que afectaban al Reino de Mallorca desde su constitución como nuevo Estado.

Había el convencimiento de que la creación de riqueza tendría efectos importantes a largo plazo. Resolvería los principales desequilibrios económicos y sociales existentes, fortalecería el Reino de Mallorca, y lo que es más importante, contribuiría a unir e implicar a todos los mallorquines, insulares, occitanos y pirenaicos, en un mismo proyecto común, facilitando una mejor vertebración política entre sus territorios, excesivamente dispersos y fragmentados. Jaime II tenía la certeza que la viabilidad y la supervivencia del Reino de Mallorca como Estado sólo era posible si se reducía su dependencia económica y política respecto a los países más poderosos de la zona.

El monarca llevó a cabo considerables reformas y medidas en beneficio de sus súbditos en todos los sectores. ${ }^{16}$ Creó un sistema monetario mallorquín, impulsó una manufactura de calidad local y reordenó el territorio en las Islas Baleares. En su propósito por atraer a la burguesía mercantil insular, también ordenó el establecimiento del primer cónsul del Reino de Mallorca en Bugía en 1302. Entre otras funciones, el cónsul se encargaba de velar por los intereses económicos de los ciudadanos mallorquines. Hasta entonces, el cónsul de la Corona de Aragón era quien se encargaba de defender a los hombres de negocios mallorquines ante la administración extranjera como representante de los catalanes. La instauración de un cónsul por parte del Reino de Mallorca suponía la limitación del control que ejercía la burguesía catalana sobre la mallorquina. ${ }^{17}$

La Corona mallorquina fue creando una red de consulados en el Reino de Granada y el Norte de África, pese a la ofensiva diplomática de la Corona de

${ }^{16}$ Jaime II también fue el impulsor de la identidad fiscal del Reino de Mallorca. Para poder llevar a cabo las reformas e inversiones, desarrolló una fiscalidad permanente en las Islas Baleares basada en la imposición indirecta, a partir de 1300. Sus medidas fiscales se constituyeron en la base de la actuación de otros futuros gobernantes mallorquines. Véase, CATEURA BENNASSER, P., «El sistema fiscal del Reino de Mallorca en los inicios de crisis» en Mayurqa, 27, Universitat de les Illes Balears, 2001, pp. 50-51.

${ }^{17}$ Consulte, ARM, RP, Deutes, 1307, f. 33r (1302), también cit. por SEVILLANO COLOM, F, «Mercaderes y Navegantes Mallorquines (siglos XIII-XV), en J. Mascaró Pasarius (coord.), Historia de Mallorca, IV, Ed. Cort, Palma de Mallorca, 1971, p. 500. Véase además, RIERA MELIS, A., «Mallorca (1298-1311), un ejemplo de planificación económica en la época de plena expansión» en Estudios Históricos y Documentos de los Archivos de Protocolos, V, Colegio Notarial de Barcelona, 1977, pp. 241-242; y TUDELA VILLALONGA, L., «El Regnat dels últims anys de Jaume II de Mallorca (1298-1311): iniciatives de la monarquia en el comerç i la indústria local», en Acta Historica et Archaeologica Medievalia, 26, Universitat de Barcelona, 2005, pp. 306-323. 
Aragón en aquellas ciudades donde iba estableciendo cónsules. Además, de la citada Bugía, la Corte de Perpiñán dispuso de cónsules en Bona, Cherchell, Constantina, Túnez y Málaga entre otras ciudades. De esta forma, buscaba reforzar la identidad nacional. La red de consulados mallorquines sólo volvería a ser controlada por la monarquía aragonesa tras la reincorporación definitiva del Reino de Mallorca. En los siguientes siglos, la Corona de Aragón amplió a un mayor número de ciudades la presencia de cónsules encargados de defender los intereses catalanes y mallorquines.

Sin embargo, las reformas debían acompañarse con la imagen exterior de un Reino fuerte, próspero, y de gran prestigio; e interior, de fuerte cohesión social y de satisfacción de la población mallorquina por los logros conseguidos por la Corona. Jaime II trató de reflejar estas imágenes a través de las construcciones arquitectónicas, mucho más visibles que las actividades iconográficas. Durante la Baja Edad Media, hay pocas representaciones iconográficas que muestren la arquitectura de las ciudades mallorquinas. ${ }^{18}$ Jaime II actuó como rex faber o soberano constructor.

El monarca proyectó una serie de construcciones arquitectónicas suntuosas en los últimos años de su gobierno, favorecido por una etapa de bonanza y prosperidad económica del Reino de Mallorca en las primeras décadas del siglo XIV. Además, habilitó las obras de las principales sedes y lugares de residencia de la Corte, como el Palacio de Perpiñán, con la creación del espacio sagrado de la capilla de Santa Cruz, y el Palacio de la Almudaina en Ciutat de Mallorques, vieja fortaleza de origen musulmán.

Las principales construcciones se levantaron en Mallorca. Jaime II creó un complejo de residencias reales dispersas entre los que se encontraban los palacios rurales de Sineu, Manacor y Valldemossa, todos ellos próximos a reservas cinegéticas. Mención especial merece el castillo de Bellver, que se edificó entre 1300 y 1309 y que destaca por su planta circular, de gran ori-

${ }^{18}$ La representación iconográfica urbana balear en la Baja Edad Media se ha reducido principalmente a varias imágenes de la ciudad gótica de Ciutat de Mallorques, entre las que se encuentran las pinturas murales del palacio barcelonés de Aguilar de finales del siglo XIII, y el retablo de San Jorge de Pere Nisard de la segunda mitad del siglo XV. Las características de estas pinturas pueden ser consultadas entre otros en: LLOMPART MORAGUES, G., «La Ciudad de Palma de Mallorca, 1468: una ciudad en un cuadro o el alarde de Pere Nisard» en La pintura gótica durante el siglo XV en tierras de Aragón y otros territorios peninsulares, Institución «Fernando el Católico», CSIC, Zaragoza, 2007, pp. 73-86; SEBASTIÁN LÓPEZ, S., «Aspectos Urbanísticos de Palma de Mallorca en la Edad Media» en Revista d'Art, n. 1, Barcelona, 1973, pp. 80-82. y TOUS MALIÁ, J., «La Evolución Urbana de Palma: una visión iconográfica», en Biblio 3W, n. 518, Universidad de Barcelona, 25 de junio de 2004, http://www.ub.es/geocrit/b3w-518.htm. 
ginalidad en la Península Ibérica. Asimismo, impulsó la edificación de la que sería la actual catedral de Mallorca, destacando especialmente la construcción de la capilla de la Trinidad, donde fue enterrado en 1311. Sus sucesores se limitaron a finalizar las obras que había iniciado, y que no concluyeron hasta mediados del siglo XIV.

Durante el período de Jaime II, se iniciaron algunas de las construcciones más características y significativas de la historia del Reino de Mallorca. Pocos monarcas dejaron huella en el espacio arquitectónico mallorquín con posterioridad. La imagen edilicia que proyectó, trataba de despertar no sólo la admiración de los extranjeros que vinieran a comerciar, sino también el sentimiento nacional de los mallorquines de pertenencia al territorio. Lamentablemente, la realidad política y económica acabarían imponiéndose, y el Reino de Mallorca se integraría rápidamente en la Corona de Aragón a mediados del siglo XIV, con una organización institucional y municipal ya configurada y un marco territorial definido, pero sin una identidad nacional que acabase perdurando en el tiempo. 